\title{
THE ASSOCIATION OF HERPES ZOSTER AND VARICELLA *
}

\author{
ERNEST L. MCEWEN, M.D. \\ CHICAGO
}

The possibilities of this subject are obviously extensive, but space limitations will not permit more than an occasional reference to the etiology, epidemiology and immunology of zoster and varicella. I shall attempt to do two things: first, to report a case of associated herpes zoster and varicella which in some of its relations is almost unique in medical literature; and second, to present certain recommendations deduced from an examination of the literature on this particular association which, if followed, would contribute to the clarification of a subject upon which there is now great confusion.

The report presented covers a case which falls into Group 3 in the classification given below: A man with zoster developed varicella which he passed on to a daughter not otherwise exposed.

\section{REPORT OF A CASE}

History:-The patient, a physician on the house-staff of a sanatorium, in early middle life, of regular habits, in good general health and with a negative medical history, presented two sets of skin lesions involving the face, the trunk, arms and legs, and the mucous membrane of the tongue. Those on the left side of the face appeared first, being preceded for about twenty-four hours by a burning pain in the left temple of such nature and severity as to suggest the possibility of an accidental contact of the part with an acid. The lesions consisted of numerous groups of vesicles, situated on a more or less diffusely reddened integument, and containing serous material; at several places the contents were hemorrhagic: By the third day the local pain was marked; there was considerable general malaise with moderate temperature; the anterior auricular and the upper anterior cervical glands became enlarged and painful; the vesicles increased in number, some appearing on the tongue; an edema of the lids closed the left eye. The condition was obviously a rather severe zoster involving the upper and middle branch of the fifth cranial nerve. Five days after the inception of the attack, at the time when the zoster was at its height, there appeared on the other parts of the face and scalp, and on the trunk, arms and legs, lesions quite evenly distributed, forty to fifty in number, consisting of macules, slightly pruritic but not painful and quite intensely erythematous, from the center of which vesicles emerged, becoming pustular in about twentyfour hours. Some of these were umbilicated, but hemorrhagic lesions were not present. The second eruption was recognized as varicella, and the patient was placed in the usual quarantine. The zoster lesions cleared up in about twelve days, leaving a few depressed scars; the varicella disappeared after about the same length of time, leaving no trace.

* Read before the Section on Dermatology at the Seventy-First Annual Session of the American Medical Association, New Orleans, April, 1920. 
Ten days after the beginning of the varicella lesions, the patient's 3-year-old daughter, who had been in contact with him before and during the quarantine, became ill with typical varicella. In the father's case there was no known exposure to chickenpox, and no knowledge of his ever having had that disease. The daughter had been exposed to the condition only through the father. As to focal infection as a cause of the zoster, there were no obvious foci to be found, but an exhaustive examination of the teeth and tonsils to determine the presence of infective material was not made.

\section{CASES REPORTED IN LITERATURE DIVIDED INTO FOUR GROUPS}

The number of cases of associated herpes zoster and varicella reported in the literature was placed by LeFeuvre ${ }^{1}$ in January, 1915, at forty. Four years later, Low ${ }^{2}$ states that over fifty have been recorded. I have been able to find somewhat less than fifty, and as a number of references were not available, the correct number is probably in the neighborhood of sixty.

For the purposes of brief review, these cases may be grouped into four classes:

1. Herpes zoster in one patient followed by varicella in others who were exposed.

2. Herpes zoster in one patient followed by varicella in the same patient not followed by varicella in others who were exposed.

3. Herpes zoster in one patient followed by varicella in the same patient followed by varicella in others who were exposed.

4. Varicella in one patient followed by herpes zoster in others who were exposed.

Group 1.-Fully two-thirds (about forty) of all reported zostervaricella cases belong to Group $1 .^{3}$ If frequency of occurrence of cases in this group may be estimated from the number of reports of cases suddenly made in England in 1913, when in the period from May to December sixteen cases were recorded in the literature, it seems probable that since 1888 , when Bokay first called attention to

1. LeFeuvre: Brit. M. J. 1:15 (Jan. 2) 1915.

2. Low: Brit. M. J. 1:91 (Jan. 25) 1919.

3. Walker: Brit. M. J. 1:1192 (May 31) 1913. Bruce: ibid. 1:1194 (May 24) 1913, and $2: 584$ (Aug. 30) 1913. Cressy: ibid. $2: 528$ (Aug. 23) 1913. Roberts : ibid. 2:584 (Aug. 30) 1913. Harrison: ibid. 2:712 (Sept. 13) 1913. Oakes : ibid. 2:712 (Sept. 13) 1913. Coates: ibid. 2:712 (Sept. 13) 1913. Willson: ibid. 2:712 (Sept. 13) 1913. Milne: ibid. 2:896 (Oct. 4) 1913. Orr: ibid. 2:1048 (Oct. 18) 1913. Busfeld: ibid. 2:1124 (Oct. 25) 1913. Bartlett: ibid. 2:1340 (Nov. 15) 1913. Quinn: ibid. 2:574 (Nov. 23) 1918. Hepworth: ibid. 2:529 (Oct. 10) 1914. Destinn : ibid. 1:633 (April 10) 1915. Low: ibid. 1: (Jan. 25) 1919. Heim: Berl. klin. Wchnschr. $49: 2349$ (Dec. 2) 1912. Richardson: Lancet 2:1732 (Dec. 13) 1913. Fordyce: Edinburgh M. J. 23:34 (July) 1919. Bokay: Wiener klin. Wchnschr. 22:1323, 1909. 
the association of the two conditions, a large number of Group 1 cases have occurred that have not been reported.

An average case of this group develops thus: The patient has an attack of zoster; in about fourteen days varicella is found in some one exposed to the zoster patient without discoverable exposure to varicella elsewhere. While these reported cases are free from serious doubt as to the correctness of the zoster and varicella diagnoses, it must be admitted that for the determination of less obvious things many are incomplete in clinical description. Such significant items as the age of the zoster patient and the location and severity of the zoster attack are not infrequently omitted. The time interval preceding the appearance of the varicella is practically always given as this seems to be accepted as an important factor in the diagnosis. In forty-eight cases of varicella originating from thirty-two cases of zoster the average interval was fourteen and one-sixth days, the extremes being two and twenty-one days. In a large number of cases the diagnosis "varicella" or "chickenpox" is given directly without description of the number and nature of the component lesions. The question of exposure of the varicella victim to other possible sources of infection is almost always considered, but in few cases is a previous varicella in the zoster patient discussed.

In explanation of these cases Bokay, ${ }^{3}$ who himself reported nine instances of the association, advances the theory that under certain unknown conditions the infective agent of varicella produces a local zosteriform eruption instead of a generalized exanthem; the zoster is thus an expression of varicella, and contagion is readily passed to others. He quotes Henoch, ${ }^{4}$ Thomas, ${ }^{5}$ Jennings ${ }^{6}$ and Swoboda, ${ }^{7}$ in support of the theory, and proposes the term "zoster varicellosa" to designate the condition. Other advocates of the theory are LeFeuvre, who suggests a clinical term of similar import to Bokay's, namely, "varicella herpetica"; and Heim, ${ }^{3}$ in whose report the varicella lesions (in a boy: source, zoster in mother) were zoniform in the right axilla, this area being also the seat of zoster-like pain.

Group 2.-This group, in which zoster in one patient is followed by varicella in the same patient, but not by varicella in others exposed, is particularly interesting in that it brings into consideration the entire subject of so-called generalized herpes zoster. In fact, it is impossible to discuss this group without including the latter condition. Under

4. Henoch: Vorlesungen über Kinderkrankheiten, Ed. 6. Berlin, 1892.

5. Thomas: In Ziemann's Handbuch der spec. Pathologie und Therapie, Vol. 2 .

6. Jennings: In Keatings Encyclopedia of Diseases of Children 1:761. 1:732.

7. Swoboda: In Pfaundler-Schlozmann: Handbuch der Kinderkrankheiten, 
various captions such as "Herpes and Varicella," "Herpes Zoster with Aberrant Vesicles," "Herpes Zoster and Chickenpox," "Association of Zoster and Chickenpox," and "Varicella Accompanying Herpes Zoster," a scant dozen cases assignable to this group have been reported by Orr, ${ }^{3}$ Williams, ${ }^{9}$ Ffrench, ${ }^{10}$ Frances and Goldberg, ${ }^{11}$ Downes, ${ }^{12}$ Corlett ${ }^{13}$ and Head. ${ }^{14}$ Some of these reports are also lacking in clinical detail, and the diagnosis of varicella does not always seem to be free from some element of doubt. In Orr's case the varicella appeared three days after the onset of the zoster and was "typical in character and distribution." In Williams' case the zoster lesions merely "looked like chickenpox," and as there appears to have been no general distribution, the case should be excluded from Group 2. In the case reported by Ffrench the interval was one day; and the only description of the generalized eruption given was the word "crop"; the diagnosis of "chickenpox complicated by herpes zoster" was made by a health officer, but Ffrench, himself, considered it a case of zoster with aberrant vesicles. In two of the cases reported by Frances and Goldberg the second eruption was "varicelliform," appearing two and three days after the onset of the zoster; in the third a varicella is described, but a time interval is not mentioned. In Downes' case the rash which appeared seven days after the beginning of the zoster was "indistinguishable from varicella," but it should be added that the patient had taken phenacetin and morphin for the zoster pain, and that several in the family. who had not had chickenpox, including a new-born babe, escaped that condition, though no attempt was made at isolation. In Corlett's reported cases, the first showed lesions "strikingly like varicella in appearance and distribution" with a five-day interval preceding; the diagnosis of varicella was concurred in by an eminent colleague; the second, with a six days' interval, showed a vesicular eruption which was simply diagnosed "varicella." The notes on the third case are scant, but the eruption corresponded to those of Cases 1 and 2 ; the fourth, after an interval of several days, showed an eruption which conformed to that of varicella. Three of these cases were in adults past middle life. Corlett apparently did not associate the two conditions etiologically, and while recognizing the rarity of the coincidence, was apparently more impressed with the unusualness of varicella occurring in adults,

\footnotetext{
8. LeFeuvre: In Guy's Hosp. Gaz. 32:101, 1918.

9. Williams: Brit. M. J. $2: 584$ (Aug. 30) 1913.

10. Ffrench: Brit. M. J. $1: 388$ (Feb. 11) 1899.

11. Frances and Goldberg: J. A. M. A. 70:1061 (Apr. 13) 1918.

12. Downes: Brit. M. J. 1:307, 1919.

13. Corlett: J. Cutan. Dis. $23: 289$ (July) 1905.

14. Head: Allbutt's System of Medicine, Ed. 1, 8:630.
} 
for he adds, without giving detailed reports, that he had seen two cases suggestive of the combination in children. (This attitude of mind toward varicella in adults was found several times in the literature usually also exerting an influence on diagnosis.) Head's patient, after a one-day interval, showed "typical chickenpox spots."

In this group of eleven cases the time interval between the two eruptions in eight instances was from one to seven days, the average being three and one-half days. It should be noted that this is much less than the average time interval given for Group 1, which was fourteen and one-sixth days. In ten, the description of the second eruption corresponds to that of varicella; in one, only the word "crop" is used; in ten, the distribution includes enough of the body surface to warrant the designation "generalized." Although the second rash was in all instances diagnosed as varicella, it is extremely significant that no case of chickenpox is recorded as having developed from exposure to combined zoster and varicella. This is so contrary to what would be expected that one may with propriety question whether in every instance the diagnosis of varicella was correct. If not varicella, these cases would fall into the category of so-called generalized herpes zoster.

This term, generalized herpes zoster, is used rather loosely in the literature. It is impossible to say exactly how many cases have been recorded. Not including the reports of bilateral zoster, ${ }^{15}$ and without considering the literature of the etiology of zoster, I have been able to find at least twenty-six cases $;^{16}$ the number is much larger if cases mentioned but not reported in detail are included. In these reports three descriptive terms are used, namely: herpes zoster with aberrant vesicles, generalized herpes zoster and universal herpes zoster. The first two terms are employed rather indiscriminately, but the last is fairly self-explanatory. A better and more inclusive designation as a substitute for this term would be "multiple herpes zoster," meaning

15. For an excellent bibliography of bilateral herpes zoster, see Stelwagon's Diseases of the Skin, Ed. 7, Philadelphia, W. B. Saunders Company.

16. Pernet: Brit. J. Dermat. 26:399, 1914. Schamberg, J. F.: Generalized Herpes, J. A. M. A. 54:532 (Feb. 12) 1910. Arkwright: Quoted in London Lancet 2:1223, 1900. Fasal: Arch. f. Derm. u. Syph. 95:27, 1909. Haslund: Nordisk. Med. Archiv., Vol. 8, 1897 ; and Kaposi's Festschrift, 1900. Weidenfeld : Arch. f. Derm. u. Syph. 96:87, 1909. Uhlmann: ibid. Ehrmann: ibid. Lipschultz: ibid, quoted in Steuer's article (see below). Mackay: Glasgow M. J. 48:278, 1897. Janselme and Leredde: In Lancet 2:822, 1898. Tenneson: Traité de Dermatologie, Paris, 1893. Girandeau: Bull. de la Soc. d. hôp., Seance du July 29, 1898, quoted by Fasal. Steuer: Wiener klin. Wchnschr. 61:1167, 1911. Molinié: These de Paris, No. 97, 1895-96. Beyer: Arch. f. Derm. u. Syph. 78:233, 1913. Tryb: Dermatologische Wchnschr. 59:983, 1914. Fischl: Arch.f. Derm. u. Syph. 118:553, 1913. Nobl: Wiener klin. Wchnschr. 24:14, 1911. Parkes Weber: Internat. Clin., Ser. 26, 3:185, 1916. 
the disturbance of more than one group - possibly all groups - of posterior root ganglions producing multiple areas of massed zoster lesions. This would include the rare instances of bilateral zoster and the oft-quoted case of universal zoster by Columbini pictured in Mracek's Handbuch. ${ }^{17}$ But the expressions "aberrant vesicles" and "generalized" zoster need to be more clearly defined. Tenneson, ${ }^{16}$ who originated the term "aberrant vesicles," says that they are few, isolated, look like those of the zoster group, are distributed irregularly at great distances from each other over the entire body, developing slowly, disappearing perhaps without being noticed, and occurring in nine out of ten cases. Crocker and Mracek confirm this stated frequency of occurrence. Molinié ${ }^{16}$ says that extensive zoster always, and moderate zoster usually, shows these vesicles, and that they do not become necrotic. Unfortunately, cases fitting Tenneson's description have repeatedly been termed "generalized herpes zoster." It is, therefore, impossible at the present time to state exactly what is meant by the two terms. Fasal ${ }^{16}$ suggests that the term "aberrant vesicles" be limited to lesions in the neighborhood of the zoster area, and that the term "herpes zoster with generalized eruption" be applied to the more extensive and intensive outbursts, thus avoiding the implication that the second rash is necessarily a zoster.

It is obvious that the "aberrant vesicles" and "generalized zoster" types may closely simulate varicella, and it is especially interesting that the rash in the generalized cases is practically always described in terms which link it with the idea of varicella. Some of these expressions are: "suspected of being smallpox but looked like chickenpox;" "like varicella;" "varicella-like spots;" "varicelliform." This similarity to varicella is apparent when the clinical details are examined more fully. Vesicles were present in fourteen cases; vesicles with opaque contents were observed in seven; with hemorrhagic contents in four; umbilicated, two; in the mouth, two; like those of chickenpox, four, and grouped, three. Papules were also present in seven. Lesions appeared in successive crops in seven; areola was present in five. The number of lesions ranged from thirty to several hundred distributed practically over all parts of the body. As to time interval, in five there was none; in two, one day; in three, from four to seven days; in four no mention of time was made; the average time interval was one and seven-tenths days. Thus it is seen that this group of "generalized" zoster is strikingly like Group 2 of our classification in which varicella was the diagnosis given for the second eruption. A significant difference is found in the time interval between eruptions: namely, one and seven-tenths and three and five tenths days. Otherwise the similarity is

17. Mracek's Handbuch der Hautkrankheiten 1:692. 
so great that one questions whether the difference is not in some instances one of terms only. A varicella erroneously called a "generalized zoster" remains a varicella and vice versa.

Group 3.-This group of our zoster-varicella classifications combines the clinical element of Groups 1 and 2 ; that is, the patient with zoster not only develops varicella himself, but passes it on to others. As mentioned above, about fifty cases in the first two groups have been reported; instances, however, which fit the requirements of Group 3 seem to be of extreme rarity. The case herewith reported is one; the generalized eruption which showed itself five days after the appearance of the zoster in a man who had never had varicella, was clinically in every detail a typical varicella, and the child who, following exposure to this zoster patient, developed varicella after a ten day's incubation period, was known positively not to have been exposed to that disease elsewhere. In the literature, up to the present, I have been able to find only two cases which might by liberal interpretation be placed in this group; neither of them is a clear-cut case. In one case reported by Grey, ${ }^{18}$ two varicellas developed after exposure to a case of right thoracic zoster, with one or two lesions on the left chest; the diagnosis of chickenpox was made after recovery and was based on the fact that these spots outside the zoster area left "scars like those of varicella." The second case is reported by Weber: ${ }^{16} \mathrm{~A}$ man with leukemia under treatment with arsenic developed a typical zoster about the right shoulder, five days later a generalized but scanty eruption of varicella-like lesions appeared over the body; a boy exposed to this patient left the hospital and in ten days became ill with varicella. Weber says: "It is worth mentioning, but it is doubtless a mere coincidence."

Group 4.-This group is a logical outgrowth of the preceding groups: If zoster can lead to varicella, why should not varicella lead to zoster? Four cases have been found recorded by Dando, ${ }^{19}$ Aikman, ${ }^{20}$ and an anomynous observer. ${ }^{21}$ Dando reports attending a man with zoster whose son had had chickenpox four weeks before; some years before in the same family he had cared for the mother who had had a zoster which appeared five weeks after a varicella in a daughter. In Aikman's report a boy returned to a boarding school with an unhealed varicella; seven days later his teacher, who had never had varicella developed a right thoracic zoster; varicella appeared also in other

18. Grey: Brit. M. J. 1:377 (Mar. 29) 1919.

19. Dando: Brit. M. J. 2:1340 (Nov. 15) 1913.

20. Aikman: Quoted by Parkes Weber; from LeFeuvre: M. J. of South Africa 9:77, 1914.

21. Guy's Hospital Gazette $27: 219,1913$. 
children. The anonymous observer reports that a boy of 13 showed a zoster two and one-half weeks after exposure to chickenpox. These cases are lacking in clinical detail and prove little or nothing; they are, however, extremely suggestive of important possibilities.

\section{COMMENTS}

From the foregoing consideration of the literature it is evident that, while an etiologic relationship in certain cases of herpes zoster and varicella must be accepted, much needs to be done toward the clarification of confused points. There is an urgent call for more careful and more complete clinical observation. Some of the items which should receive closer attention from clinicians are:

Since every patient with zoster has varicella as a possible causative factor and vice versa, inquiry should always be made of a zoster patient regarding possible exposure to and a previous attack of varicella; and every varicella patient should be questioned as to possible exposure to a zoster victim and as to previous zoster attacks.

To check up on the theory of Bokay, Heim and others, every varicella case should be examined with special reference to a possible grouped or zonaform distribution of lesions and to a history of neuralgic pain in such lesions. Incidentally, adult years must not be given undue weight in excluding a varicella.

In order to establish the correctness of the statements of Tenneson, Crocker and others as to the frequency of the so-called "aberrant vesicles," every zoster patient should be examined daily, if possible, for the presence of lesions outside the zoster area. If aberrant vesicles are found or if more extensively distributed lesions appear, in order to determine the nature of the second eruption and to establish a sound basis for differential diagnosis, a complete observation should be made concerning time relationship of the two eruptions; possible influence of drugs used in treatment; the condition of the zoster lesions when the general lesions appeared; number of the latter and positional relation to the zoster area; type or types of lesions in the general eruption; the symptom of pain; appearance in crops and observation as to whether the lesions are hemorrhagic, umbilicated, necrotic or surrounded by an areola. Every detail that might be of value in differentiating the zoster vesicle from the varicella vesicle should be searched for and noted.

Finally, as an essential step in clearing away the haze which envelops the present conception of "generalized herpes zoster," that term should be abandoned as indefinite and inaccurate and a new nomenclature established. This group should be rearranged under the captions given above, namely: (a) Herpes zoster with aberrant vesi- 
cles, restricting the lesions to the neighborhood of the zoster area as suggested by Fasal instead of the wider distribution of the original definition; $(b)$ herpes zoster attended with a general eruption, and (c) multiple herpes zoster, to include bilateral and universal cases. ${ }^{22}$

\section{ABSTRACT OF DISCUSSION}

Dr. Oliver S. Ormsey, Chicago: About ten years ago I saw a patient who presented a typical and marked case of herpes zoster of the face and scalp, and on the fourth day of the zoster a generalized varicella-like eruption developed. I have never satisfied myself as to what this might be, but it belongs in one of the groups described by Dr. McEwen.

Dr. Everetr S. Lain, Oklahoma City: A group of diseases of which herpes zoster is one, no doubt has its etiology based on some toxic product of bacterial nature. It can now be easily understood from the reports that have been made, why varicella, variola and other diseases may possibly have herpes zoster associated with them.

Dr. George P. Lingenfelter, Denver: A few months ago I saw a case of undoubted herpes zoster associated with marked neuralgic pain. This patient had been exposed to smallpox some days before. Five days later he developed typical smallpox.

Dr. J. M. KING, Nashville, Tenn.: In pneumonia, concurrent with the infection, herpes simplex develops in 33 per cent. of cases, due, no doubt, to the pneumococcus. Why could there not be an organism in varicella which has a predilection for nerve tissue, thus producing herpes zoster? Both varicella and herpes zoster produce immunity. Why could not the organism of varicella produce herpes zoster just as the pneumococcus produces herpes simplex?

Dr. Walter J. Highman, New York: Herpes is a disease sui generis and has no connection with herpes zoster. The pathology is similar. True herpes zoster has no connection with any other disease. The zoster may be due to the same micro-organism that causes the varicella; in other words, they may be different clinical expressions of the same agency. but the zoster-like eruptions are not true zoster. The latter never recurs.

DR. Richard L. Sutton, Kansas City, Mo.: I thought herpes zoster was usually due to infection or to injury of one of the posterior ganglions. I did not know that it was a disease sui generis.

Dr. Ernest L. McEwen, Chicago: I made no attempt to discuss etiology for I found the subject so broad that I could not do so in the time allowed. I am convinced that herpes zoster may have a number of infective causes.

22. The following references were not available:

LeFeuvre: M. J. of South Africa 12:77, 1914; ibid. 13:133, 1918.

Minet and LeClerque: Clinique 6:100, 1911.

Janselme and Touraine: Bull. de la Soc. francais, de Derm. et syph. 25:351 (July 2) 1914.

Janselme and Leredde: Bull. et mém. Soc. méd. de hôp. de Paris. $15: 619,1898$.

Watson: Guy's Hosp. Gaz. 29:186 (Apr. 24) 1915.

Wainwright: ibid. 27, May 10, 1913.

Heatherby: ibid. 28, April 25, 1914. 
It is possible that the organism of varicella and also of smallpox is capable, under certain conditions, of producing the clinical picture of zoster. The real purpose of this paper was to emphasize the following: first, that these cases are occurring much more frequently than the literature indicates; second, that the reports in the literature are incomplete and insufficient; third, that it is imperative that clinicians and pathologists should examine most thoroughly these cases of zoster combined with other eruptions in order to find out everything possible about them; fourth, the desirability of abandoning the term "generalized herpes zoster," and substituting for it the three terms given, as covering more accurately all the types observed. It is only by more careful and complete observation that we will arrive at a more accurate knowledge of the association of herpes zoster and varicella. 